\title{
Properties and Internal Curing of Concrete Containing Recycled Autoclaved Aerated Lightweight Concrete as Aggregate
}

\author{
Teewara Suwan ${ }^{1,2}$ and Pitiwat Wattanachai ${ }^{1}$ \\ ${ }^{1}$ Department of Civil Engineering, Faculty of Engineering, Chiang Mai University, 239 Huay Kaew Road, Muang District, \\ Chiang Mai 50200, Thailand \\ ${ }^{2}$ Center of Excellence for Natural Disaster Management (CENDIM), Chiang Mai University, 239 Huay Kaew Road, \\ Muang District, Chiang Mai 50200, Thailand \\ Correspondence should be addressed to Pitiwat Wattanachai; pitiwat@eng.cmu.ac.th
}

Received 1 June 2017; Accepted 10 July 2017; Published 20 August 2017

Academic Editor: Tung-Chai Ling

Copyright (c) 2017 Teewara Suwan and Pitiwat Wattanachai. This is an open access article distributed under the Creative Commons Attribution License, which permits unrestricted use, distribution, and reproduction in any medium, provided the original work is properly cited.

\begin{abstract}
Global warming is a vital issue addressed to every sector worldwide, including the construction industry. To achieve the concept of green technology, many attempts have been carried out to develop low-carbon footprint products. In the construction sector, Autoclaved Aerated Concrete (AAC) has become more popular and been manufactured to meet the construction demand. However, errors from manufacturing process accounted for approximately 3 to $5 \%$ of the AAC production. The development of AAC waste as lightweight aggregate in concrete is one of the potential approaches which was extendedly studied in this paper. The results showed that the compressive strength of AAC-LWA concrete was decreased with an increase in volume and coarse size. The optimum mix proportion was the AAC aggregate size of $1 / 2^{\prime \prime}$ to $3 / 8^{\prime \prime}$ with 20 to $40 \%$ replacement to normal weight aggregate. Internal curing by AAC-LWA was also observed and found to provide sufficient water inside the specimens, leading to an achievement in higher compressive strength. The main goal of this study is not only utilising unwanted wastes from industry (recycling of waste materials) but also building up a new knowledge of using AAC-LWA as an internal curing agent as well as the production of value-added lightweight concrete products.
\end{abstract}

\section{Introduction}

To achieve the concept of green construction technology, many attempts have been carried out to develop low-carbon footprint products or techniques. An approach of transforming wastes from any industrial sectors to become a new raw starting material for other industries has received much more attention as a zero-waste society. Commonly, the simplest eliminating of industrial wastes is to utilise them as cement or concrete replacement, for example, cement additives or concrete aggregates. In Thailand, although a conventional masonry wall is made from local clay-bricks, with launching of Lightweight Autoclaved Aerated Concrete (AAC) blocks they turn into a new choice for engineers and builders, therefore becoming more and more popular in the construction industry. However, it was reported that scraps and wastes from overall AAC block production accounted for approximately 3 to $5 \%$ (58 tonnes monthly), resulting in a huge number of AAC residues heading directly to a landfilled site (Figure 1). Developing AAC wastes as a lightweight aggregate in concrete production is one of the potential approaches that not only is beneficial for utilising industrial by-products and the reduction of energy consumption but also is beneficial for a strength improvement by internal curing and a reduction of final concrete weight $[1,2]$.

External curing is a common method to acquire sufficient Portland cement hydration, which can be achieved by preventing moisture loss on surfaces, wrapping with any wetcovers, or even submerging the concrete samples in the water bath. However, in some cases, the effectiveness of external curing may be limited due to an unsatisfied penetration of curing-water into the samples by physical barrier or geometry of the concrete components [3]. Internal curing is an alternative approach introducing internal water reservoir 

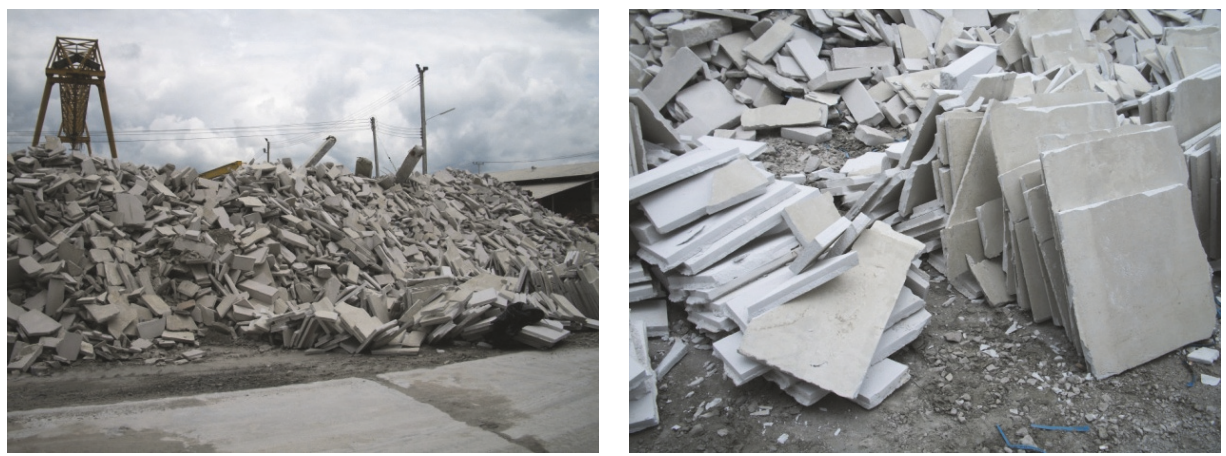

FIGURE 1: Scraps of AAC block production.

for curing purpose inside the concrete mixtures. It has already been proved that internal curing can significantly enhance the strength and reduce an autogenous shrinkage of the final concrete products $[4,5]$. Any porous lightweight material can be used as an internal curing aggregate (e.g., vermiculite, perlite, pumice, scoria, expanded shale, expanded clay, and crushed-AAC wastes) $[6,7]$ as they could absorb water during preparation and mixing and then gradually release reserved water inside the mixtures during hardening process [8]. Moreover, the rough surface and coarse pore structure of those lightweight aggregates can also contribute to an interlocking manner on transition zones between cement paste and aggregate (interconnected surfaces), leading to an improvement in mechanical properties [9].

The main aim of this paper is to utilise available local AAC waste as a lightweight aggregate in concrete production which could allow converting industrial wastes into value-added products. Lightweight and highly uniformly distributed porosity are key characteristics of AAC that could serve as an internal curing material to provide sufficient curing condition for concrete construction. The suitable sizes and optimum replacement percentage of AAC aggregate were investigated as well as the final properties of fresh and hardened concrete during the internal curing approach.

\section{Materials and Preparations}

Portland cement was a commercial grade type I with a specific gravity of 3.15. Local river sand was used as a fine aggregate with specific gravity and fineness modulus of 2.39 and 2.90 , respectively. The moisture content of sand was $0.80 \%$ with a bulk density of $1,645 \mathrm{~kg} / \mathrm{m}^{3}$. Coarse aggregate was commercial grade gravel from local suppliers. The specific gravity, moisture content, and bulk density were $2.70,0.50 \%$, and $1,540 \mathrm{~kg} / \mathrm{m}^{3}$, respectively. AAC wastes were collected from PCC Autoclave Concrete Company Limited, Chiang Mai, Thailand. Its specific gravity was 1.06 with a dry-unit weight of $360 \mathrm{~kg} / \mathrm{m}^{3}$. As-received AAC, with a water absorption value of 28 to $30 \%$, was crushed into a smaller size by a standard Jaw crusher (Figure 2).

The gradation of AAC coarse aggregates was then analysed by the US standard sieve analysis. The effective coarse size used in this study was between $3 / 8^{\prime \prime}\left(9.5 \mathrm{~mm}\right.$.) and $3 / 4^{\prime \prime}$
TABLE 1: Grading of crushed-AAC aggregates.

\begin{tabular}{lc}
\hline Sieve size $(\mathrm{mm})$. & Percent retained on the sieve \\
\hline $2^{\prime \prime}(50.80)$ & 1.31 \\
$1^{\prime \prime}(25.40)$ & 9.18 \\
$3 / 4^{\prime \prime}(19.05)$ & 18.22 \\
$1 / 2^{\prime \prime}(12.70)$ & 20.12 \\
$3 / 8^{\prime \prime}(9.53)$ & 11.35 \\
$\# 4(4.75)$ & 11.14 \\
Pan & 28.67 \\
\hline
\end{tabular}

TABLE 2: Mixture labels and descriptions.

\begin{tabular}{lc}
\hline Label & Description \\
\hline NC & $\begin{array}{c}\text { Normal weight aggregate concrete } \\
\text { Lightweight aggregate }\end{array}$ \\
LWA20 & $\begin{array}{c}\text { Concrete with } 20 \% \text { lightweight aggregate } \\
\text { replacement }\end{array}$ \\
LWA40 & Concrete with $40 \%$ lightweight aggregate \\
& replacement \\
LWA60 & Concrete with $60 \%$ lightweight aggregate \\
replacement
\end{tabular}

(19.0 mm.), which accounted for around $50 \%$ of the overall amount of AAC aggregates and has an average fineness modulus of 7.20 (Table 1 ). It is noted that the majority of effective AAC-LWA size values were $3 / 4^{\prime \prime}, 1 / 2^{\prime \prime}$, and $3 / 8^{\prime \prime}$, and the size classes (as indicated with S1 to S4) of coarse aggregates replacement were therefore employed in the experiment. Mixture labels and descriptions of concrete mixtures, including size classes of AAC-LWA, are illustrated in Table 2.

The coarse aggregate, commercial grade, and size distributions are in the comparison of ASTM C33 with size number 

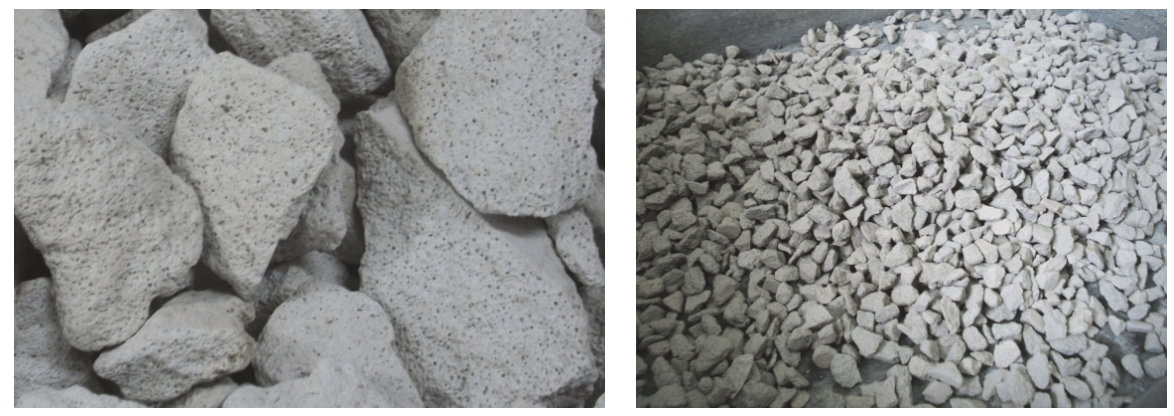

FIGURE 2: Crushed-AAC scraps into AAC aggregates.

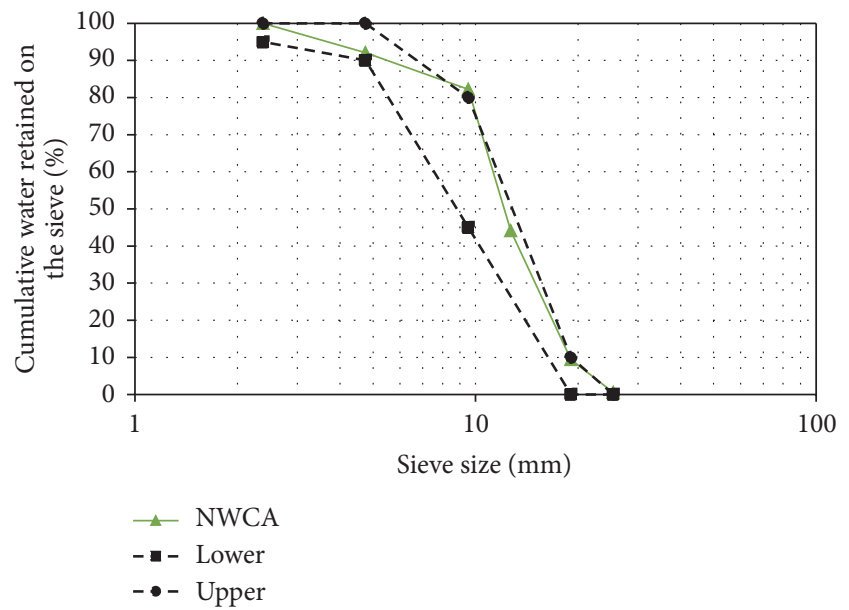

FIGURE 3: Size distribution of normal weight coarse aggregates (NWCA) used in accordance with ASTM C33 Size Number 67.

67. Figure 3 shows the size distribution of normal weight coarse aggregates (NWCA) used in NC mixture. It was found that the size distributions of normal weight aggregate are between $1 / 2^{\prime \prime}$ and $3 / 8^{\prime \prime}$ and mostly filled in the upper and lower boundaries of ASTM C33 size number 67 standard. In addition, as varied in class size of $\mathrm{S} 1-\mathrm{S} 4$, the size distributions of AAC-LWA replacement to normal weight aggregate by 20 , 40, and 60\% (LWA20, LWA40, and LWA60) are also plotted against upper and lower boundaries of ASTM C33 number 67 criteria.

As specific AAC-LWA class sizes (S1-S4) were replaced to a normal gradation of commercial grade gravel, the graphs of size distribution therefore started to shift to the upper limit of the ASTM C33 boundaries (Figure 4). It can be seen that a bundle of all LWA20 class sizes are aligned closely inside the upper boundary (Figure 4(a)). Moreover, the lines of size distribution were apparently shifted to the right beyond the upper limit, when the amount of AAC-LWA replacement increased from LWA40 (Figure 4(b)) to LWA60 (Figure 4(c)) in all class sizes. Thus, the presence of AAC-LWA aggregates does not only affect the overall gradation of concrete coarse aggregate but could also affect the mechanical properties of the final result of hardened concrete.

\section{Experimental Details}

3.1. Mixture Designations. Mixture designation was carried out following ACI 211.1 standard for concrete mixing. In controlled mixture (Normal Concrete, NC) with water-tocement $(\mathrm{w} / \mathrm{c})$ ratio of 0.35 , normal weight aggregates were added with the largest particle size of $3 / 4^{\prime \prime}$. The required concrete slump was set to 5 to $10 \mathrm{~cm}$. Apart from that, in the mixtures with AAC wastes as lightweight aggregates (AAC-LWA), the volume of normal weight aggregates was substituted by the saturated surface-dry (SSD) AAC-LWA, namely, 20, 40, and 60\%, respectively. It is noted that the total weight of AAC-LWA replacement was calculated from the same volume of normal aggregate in a cubic meter of concrete. For example of $20 \%$ AAC-LWA replacement (LWA20), as bulk density of normal weight aggregates and AAC-LWA were 1,540 and $360 \mathrm{~kg} / \mathrm{m}^{3}$, respectively, $188 \mathrm{~kg}$ of normal weight aggregates was replaced by $46 \mathrm{~kg}$ of AACLWA. All concrete mixtures were mixed in a tilting drum mixer until reaching suitable conditions. The fresh concrete was then carried out for workability testing and placed in the prepared moulds. After 24 hours, all concrete samples were demoulded and kept in specific designed-curing conditions, water and air curing. Mixture proportions are as presented in Table 3.

3.2. Analytical Methods. Properties of fresh concrete were carried out by slump test and flow test. Concrete slump test was done with ASTM C143. The slump value of $10 \mathrm{~cm}$. was set in accordance with ACI 213R-87, which is recommended for the construction of slab, column, and bearing wall structures. Flow ability of concrete was measured by using flow table along with ASTM C124 standard. Properties of hardened concrete were carried out with both standard and minute compressive strength tests. After demoulding (in the next 24 hours), all samples were cured in water or in the air until reaching their testing ages of $1,3,7$, and 28 days. Weight and dimension of all samples were measured before further handling for the apparent density calculation. Standard compressive strength test of all cylindrical specimens $(15 \mathrm{~cm}$ dia. and $30 \mathrm{~cm}$ height) was obtained by using Universal Testing Machine (UTM) in accordance with ASTM C39. An optical microscope was used to observe interfacial transition zone (ITZ) of AAC-LWA and cement paste. 


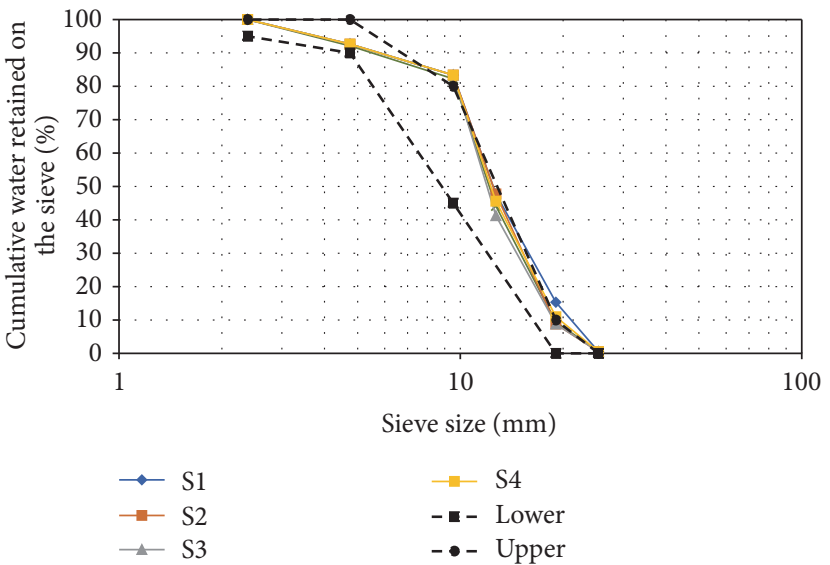

(a)

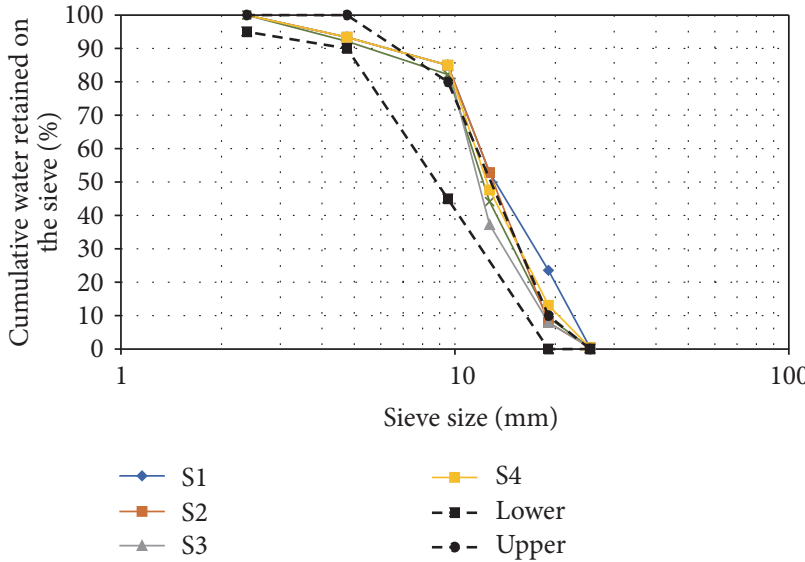

(b)

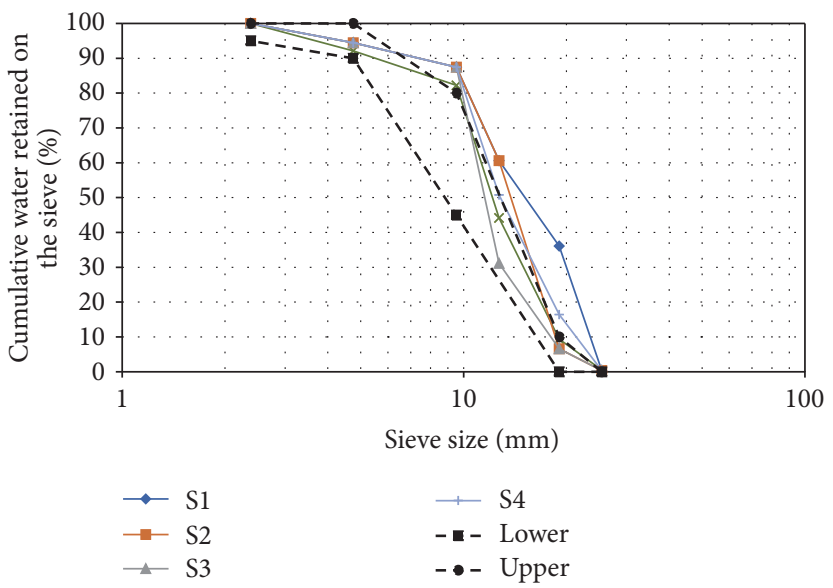

(c)

Figure 4: Size distribution of AAC-LWA of (a) LWA20, (b) LWA40, and (c) LWA60 in accordance with ASTM C33 Size Number 67. The green curve refers to the normal weight coarse aggregates (NWCA) (as shown in Figure 3), for comparison to S1-S4.

TABLE 3: Details of mixture designation $\left(\mathrm{kg} / \mathrm{m}^{3}\right)$.

\begin{tabular}{|c|c|c|c|c|c|c|c|}
\hline Mixture & $\begin{array}{c}\text { ACC-LWA } \\
\text { replacement (\%) }\end{array}$ & Class size & $\begin{array}{c}\text { Portland } \\
\text { cement }\end{array}$ & Water & $\begin{array}{c}\text { Fine } \\
\text { aggregate }\end{array}$ & $\begin{array}{c}\text { Coarse } \\
\text { aggregate }\end{array}$ & $\begin{array}{c}\text { ACC } \\
\text { aggregate }\end{array}$ \\
\hline $\mathrm{NC}$ & - & - & 571 & 200 & 588 & 938 & - \\
\hline \multirow{4}{*}{ LWA20 } & 20 & S1 & 571 & 200 & 588 & 750 & 46 \\
\hline & 20 & S2 & 571 & 200 & 588 & 750 & 46 \\
\hline & 20 & S3 & 571 & 200 & 588 & 750 & 46 \\
\hline & 20 & S4 & 571 & 200 & 588 & 750 & 46 \\
\hline \multirow{4}{*}{ LWA40 } & 40 & S1 & 571 & 200 & 588 & 563 & 93 \\
\hline & 40 & S2 & 571 & 200 & 588 & 563 & 93 \\
\hline & 40 & S3 & 571 & 200 & 588 & 563 & 93 \\
\hline & 40 & S4 & 571 & 200 & 588 & 563 & 93 \\
\hline \multirow{4}{*}{ LWA60 } & 60 & S1 & 571 & 200 & 588 & 375 & 139 \\
\hline & 60 & S2 & 571 & 200 & 588 & 375 & 139 \\
\hline & 60 & S3 & 571 & 200 & 588 & 375 & 139 \\
\hline & 60 & S4 & 571 & 200 & 588 & 375 & 139 \\
\hline
\end{tabular}




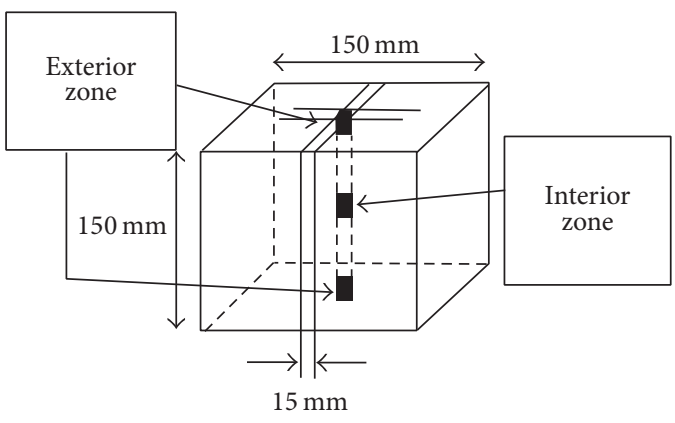

FIgURE 5: Cutting layout of $15 \times 15 \times 150 \mathrm{~mm}$. prisms.

Minute compressive strength $(3 \times 3 \times 3 \mathrm{~mm}$. cubic specimen) was introduced and carried out in this test to identify the effect of AAC-LWA on internal curing [10]. To prepare minute strength test samples, the $150 \times 150 \times$ $150 \mathrm{~mm}$. concrete cube was mixed and cured in designedconditions. Three locations of the concrete cube (exterior zone and interior zones) were cut into $15 \times 15 \times 150 \mathrm{~mm}$. prisms (Figure 5). Each prism was then sliced into $3 \mathrm{~mm}$ thick layers with the dimensional length of $3 \times 15 \times 15 \mathrm{~mm}$., namely, $\mathrm{L} 1, \mathrm{~L} 2$, and L3. It is noted that L1 was a layer right next to the AAC-LWA, while L2 and L3 were further aligned over (Figure 6). Those layers (L1, L2, and L3) were finally cut into 3 $\times 3 \times 3 \mathrm{~mm}$. cubes (Figure 7 ) and then tested with a standard proving ring attached to the UTM.

\section{Results and Discussions}

4.1. Slump Test. The results of concrete slump test are illustrated in Figure 8 . The AAC-LWA size classes, as indicated by S1, S2, S3, and S4 (see Table 2), had no significant difference in the test. The slump of controlled concrete (NC) was $5.80 \mathrm{~cm}$., while slump values of AAC-LWA concrete tended to increase with a higher percentage of AAC aggregate replacement, for example, from around $7.50 \mathrm{~cm}$. (LWA20) to around $10.60 \mathrm{~cm}$. (LWA60). In fact, sharp shape and rough surface of AACLWA could decrease the slump value due to interlocking and internal friction among materials [11]. However, in this case, the slump value was mainly dominated by water retainability, extra water on the surface of AAC particles. Water-to-cement ratio was therefore raised, leading to an increase of concrete slump value. A similar result was also reported by Singh and Siddique (2016) that highly absorption materials (e.g., coalbottom ash) can act as a water reservoir and could raise the final w/c ratio of concrete mixtures [12].

4.2. Flow Test. There was no significant difference in flow ability between controlled mixture (NC) and AAC-LWA mixtures. An average flow of AAC-LWA concrete seemed to be slightly decreased when the AAC aggregate replacement increased. The average flow value of NC was $53.3 \%$ while average flow values of LWA20, LWA40, and LWA60 mixtures were $55 \%, 56 \%$, and 53\%, respectively (Figure 9). However, as the flow values were in the range of 50 to $100 \%$, the AAC-LWA concrete mixtures were classified in medium consistency which could easily be placed and compacted into the moulds during a casting process.

4.3. Apparent Density of Concrete Mixtures. As presented in Figure 10, the apparent density of controlled mixture (NC) was around $2,380 \mathrm{~kg} / \mathrm{m}^{3}$ at 28 days of age. Apart from that, the overall apparent density of LWA20 concrete was slightly decreased approximately 3 to $4 \%$ to around 2,290 to $2,310 \mathrm{~kg} / \mathrm{m}^{3}$ when compared with NC mixture. With LWA40 and LWA60 mixtures, the apparent density was continuously decreased by 8 to $9 \%\left(2,160\right.$ to $\left.2,180 \mathrm{~kg} / \mathrm{m}^{3}\right)$ and 13 to $15 \%\left(2,030\right.$ to $\left.2,070 \mathrm{~kg} / \mathrm{m}^{3}\right)$, respectively. The similar results were reported by Hossain et al. (2011) and Topçu and Işikdağ (2008) whose substituted normal weight aggregates by pumice and perlite as concrete coarse aggregates [13]. It can be concluded that the overall density of AAC-LWA concrete was significantly decreased because of LWA replacement as its density was just $360 \mathrm{~kg} / \mathrm{m}^{3}$. In contrast, the compressive strength is the next issue which needs to be considered as the most crucial properties of hardened concrete.

4.4. Standard Compressive Strength Test. The standard compressive strength test by using cylindrical specimens was carried out at $1,3,7$, and 28 days of age. The comparative strength measurement between water and dry-air curing, including its size classes, was studied and is presented in Figures 11(a)-11(c).

It can be clearly seen that all mixtures cured in water achieved higher strength than that of mixtures cured in the dry-air as more degree of hydration was obtained [14]. The size class of S4-AAC aggregate (see Table 2) received the highest strength among S1, S2, and S3 classes due to a well gradation of the coarse aggregates in concrete mixtures according to ASTM C33 number 67. More compact structure was also achieved as well as an appropriated interlocking of well-graded coarse aggregate. Comparable strength improvement was obviously obtained from the higher density of hardened cement paste in the interfacial transition zone (ITZ) by internal curing [15]. The examples of normal-bonding (NWCA) and well-bonding (AAC-LWA) are as presented in Figure 12. It can be seen that the failure of normal-bonded NWCA occurred at cement paste, while well-bonded AACLWA was at AAC aggregate. Apart from the strength property of each aggregate, AAC-LWA clearly exhibited a terrific bonding performance at ITZ. Nevertheless, the final strength of AAC as aggregate concrete was decreased when the amount of AAC-LWA increased because AAC has extremely low load bearing capacity when compared with normal weight aggregate.

4.5. Minute Compressive Strength Test. Minute compressive strength is a technique used to verify an effect of internal curing by porous aggregate in the concrete mixtures. The compressive strength of $3 \times 3 \times 3 \mathrm{~mm}$. cube specimens of LWA20, LWA40, and LWA60 mixtures (all with S4 class size, cured in the air) were tested and presented in Figure 13. It can be apparently seen that the strength of samples collected from the exterior zone obtained lower strength than that 


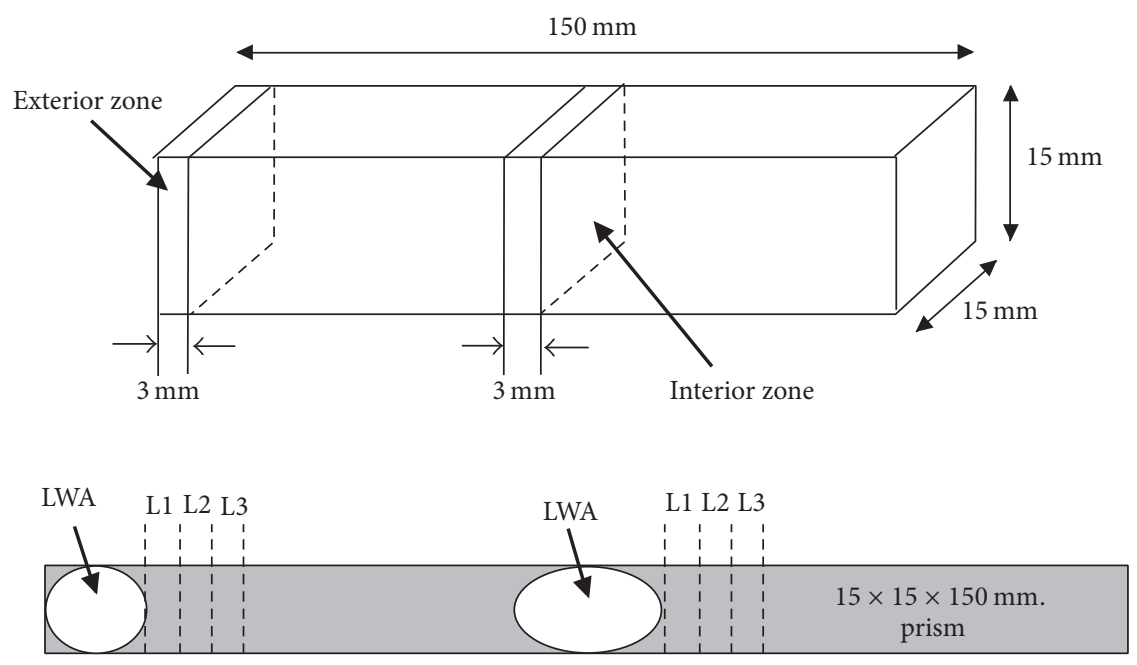

Exterior zone

Interior zone

Figure 6: Cutting layout of $3 \times 15 \times 15 \mathrm{~mm}$. layers (L1, L2, and L3).
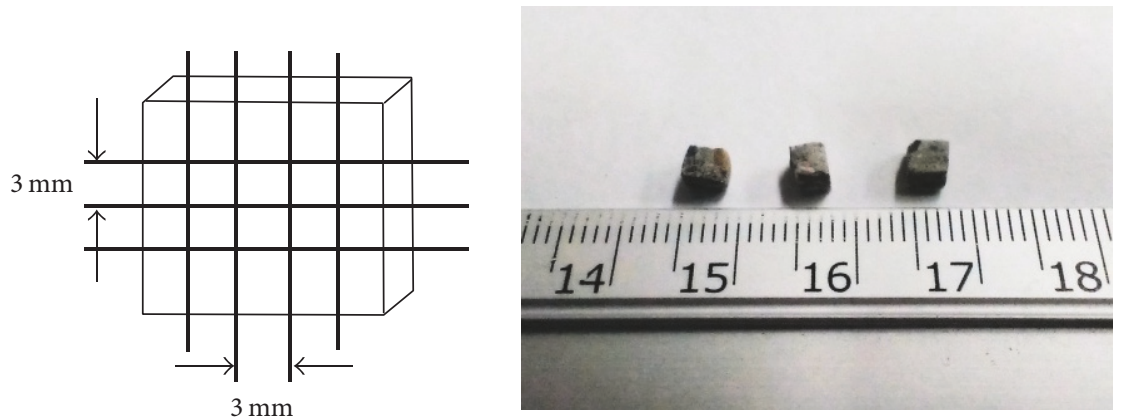

Figure 7: Cubic specimens in $3 \times 3 \times 3 \mathrm{~mm}$. size.

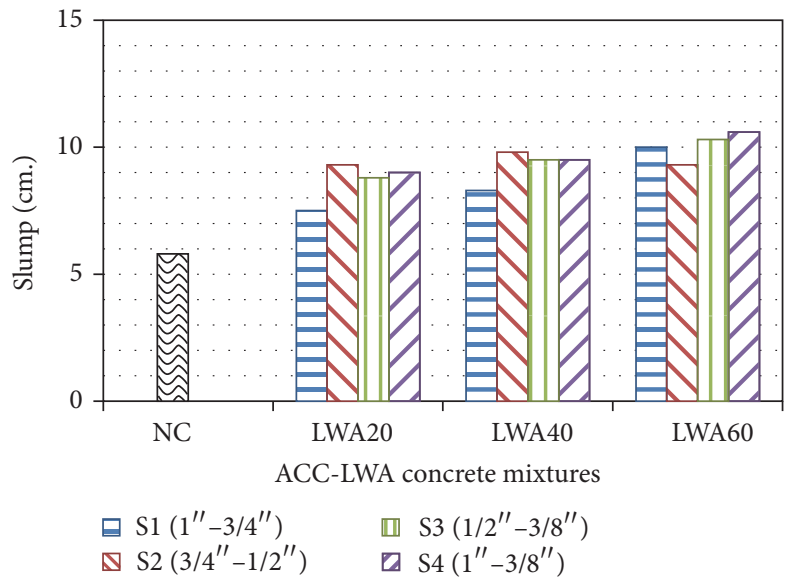

FIGURE 8: Slump values of NC and LWA mixtures.

of the interior zone. Moreover, the strength of L1 sample (L1; the layer next to AAC aggregate) obviously achieved higher mechanical strength than those of the faraway layers, L2 and L3 (see Figure 6). In general, more completion of internal hydration process of AAC-LWA could be achieved

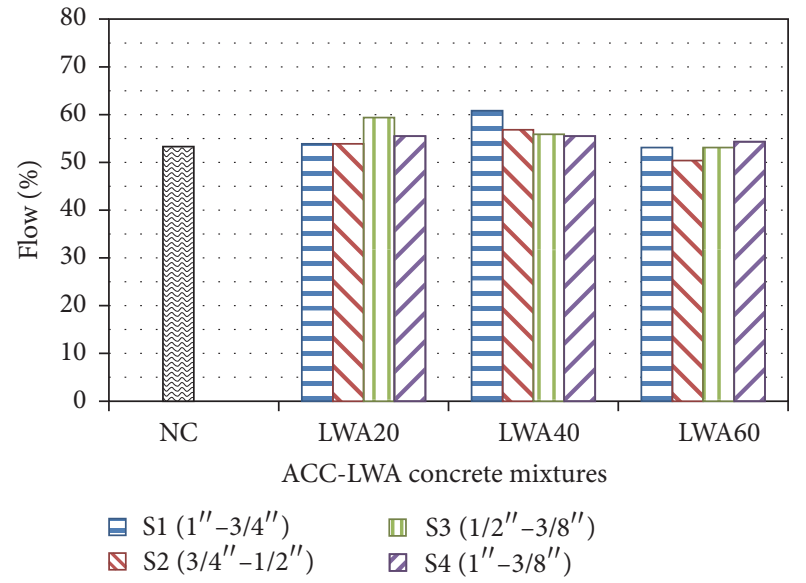

FIGURE 9: Flow values of NC and LWA concrete mixtures.

by water retainability in the concrete mixture. Especially for porous aggregates, extra water for internal curing purpose was not only obtained from water absorption but also from water adsorption, which directly affects the curing-water of concrete in later stage [16]. Moreover, the internal curing 
TABLE 4: Differential percentage of minute compressive strength in layer 1 (L1) between 7 and 28 days of age.

\begin{tabular}{|c|c|c|c|c|c|c|c|c|c|c|c|c|}
\hline \multirow{3}{*}{ Mixtures } & \multicolumn{6}{|c|}{ Air curing (AC) } & \multicolumn{6}{|c|}{ Water curing (WC) } \\
\hline & \multicolumn{3}{|c|}{ L1 Ext. (MPa) } & \multicolumn{3}{|c|}{ L1 Int. (MPa) } & \multicolumn{3}{|c|}{ L1 Ext. (MPa) } & \multicolumn{3}{|c|}{ L1 Int. (MPa) } \\
\hline & $7 \mathrm{~d}$ & $28 \mathrm{~d}$ & $\% \Delta$ & $7 \mathrm{~d}$ & $28 \mathrm{~d}$ & $\% \Delta$ & $7 \mathrm{~d}$ & $28 \mathrm{~d}$ & $\% \Delta$ & $7 \mathrm{~d}$ & $28 \mathrm{~d}$ & $\% \Delta$ \\
\hline NC & 0.64 & 0.84 & 31.75 & 0.95 & 1.30 & 36.78 & 0.77 & 1.21 & 57.22 & 1.03 & 1.54 & 49.48 \\
\hline LWA20 & 0.83 & 1.12 & 34.00 & 1.12 & 1.69 & 51.10 & 1.11 & 1.48 & 33.33 & 1.41 & 2.01 & 42.08 \\
\hline LWA40 & 0.93 & 1.00 & 7.24 & 1.30 & 1.55 & 19.55 & 1.26 & 1.32 & 4.73 & 1.57 & 1.73 & 10.59 \\
\hline LWA60 & 0.93 & 1.13 & 21.37 & 1.23 & 1.62 & 31.42 & 1.15 & 1.43 & 25.06 & 1.39 & 1.80 & 29.04 \\
\hline
\end{tabular}

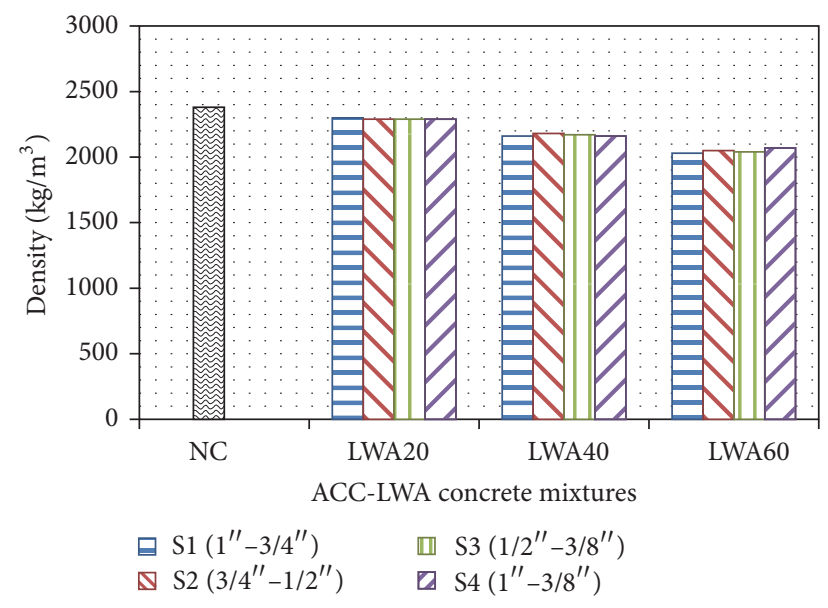

FIGURE 10: Apparent density of NC and LWA concrete mixtures.

process would also occur with "capillary suction" of which the transferring of water occurs from larger pores to the smaller ones. In this study, the capillary pores of AAC aggregates (50 to 100 microns, $\mu \mathrm{m}$ ) were larger than that of average cement paste pores (1 to 100 nanometers, $\mathrm{nm}$ ).

By this condition, some reserved water in AAC aggregates would, therefore, be transferred to cement paste across ITZ, increasing hydration level to the cement binders. The strength improvement in later age was mainly influenced by more C$\mathrm{S}-\mathrm{H}$ formation and denser microstructures [9]. The usage of AAC-LWA in saturated surface-dry (SSD) condition in this study would provide higher strength in all cases than the asreceived/dry AAC-LWA [15]. The reasons are that as-received AAC-LWA could actively absorb the water in the system during its initial stage of mixing. Micropores and incomplete microstructures would appear on ITZ, leading to an adverse effect on the final properties of concrete [15]. The same trends and results were obtained by the minute compressive strength of S4-class size of LWA20, LWA40, and LWA60 cured in water. As far as sufficient curing water was served from both external and internal sides, the average strength of $3 \times 3 \mathrm{~mm}$. cube was thus slightly higher than the others cured in the dryopen air condition (Figure 14).

4.6. The Strength Development and a Relationship between Standard and Minute Compressive Strength. The strength development of layer 1 (L1) minute compression test over 7 and 28 days is presented in Table 4. While keeping NC as a reference mixture, the LWA20 achieved the greatest difference of strength development in all conditions at 34.00\% (AC L1 Ext.), 51.10\% (AC L1 Int.), 33.33\% (WC L1 Ext.), and $42.80 \%$ (WC L1 Int.). A huge differentiation of the L1 minute compressive strength can be observed between exterior and interior zones of LWA20 (26.98\% and 35.32\%) and LWA40 $(39.03 \%$ and $54.99 \%)$ mixtures as illustrated in Table 5. It is obviously seen that the minute compressive strength of the air curing $(\mathrm{AC})$ condition can be improved with internal curing regimes, especially for the interior zone. The optimum AACLWA proportions, which would receive the most benefit from internal curing, are in the range of LWA20 to LWA 40 mixtures.

In contrast, the highest minute compressive strength of layer 1 (L1) was also plotted against standard cylindrical compressive strength with 54 class size at 7 and 28 days of age. Figure 15 presents the relationship of that minute and standard compressive strength of specimens cured in the dry-air curing condition (AC) in both their exterior zone (Figure 15(a)) and interior zone (Figure 15(b)). As mentioned earlier in Section 4.4, the average standard compressive strength of AAC-LWA concrete decreased when the amount of AAC-LWA replacement increased from $35.1 \mathrm{MPa}(7 \mathrm{~d})$ and 41.2 $\mathrm{MPa}(28 \mathrm{~d}$ ) in LWA20 mixtures to around $26.2 \mathrm{MPa}$ (7 d) and 28.1 MPa (28 d) in LWA60 mixtures. However, it is clearly seen that LWA20 and LWA40 mixtures seem to achieve higher strength than that of normal weight aggregate concrete (NC).

Minute compressive strength (as presented in Section 4.5) of the interior zone is clearly higher than the exterior one due to the internal curing of AAC-LWA with the highest value of LWA20 mixture. The investigation suggested that the $20 \%$ to $40 \%$ AAC-LWA replacement (LWA20 and LWA40) could be an optimum proportion for AAC-LWA concrete.

By this, it can be explained that those proportions mainly achieved the superior strength from normal weight aggregate while the suitable amount AAC aggregate replacement served the extra amount of water for internal curing to the cement paste. An increase of C-S-H formation not only strengthens the concrete matrices but also provides a wellbonding between AAC aggregate and cement paste at their ITZ. The similar trend of strength development was found in the specimens cured in water curing condition (WC) as shown in Figure 16. Additionally, as mentioned before, overall compressive strength of both minute and standard specimens was significantly higher than that of dry-air curing as sufficient water for curing purpose was obtained. Despite 


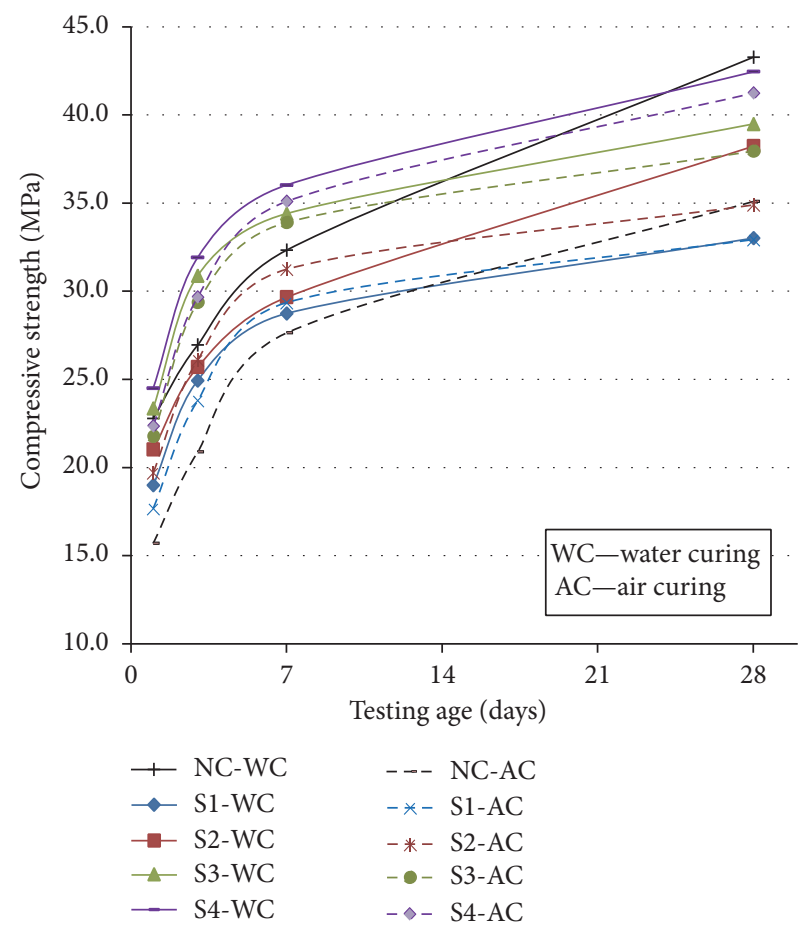

(a) Compressive strength of LWA20

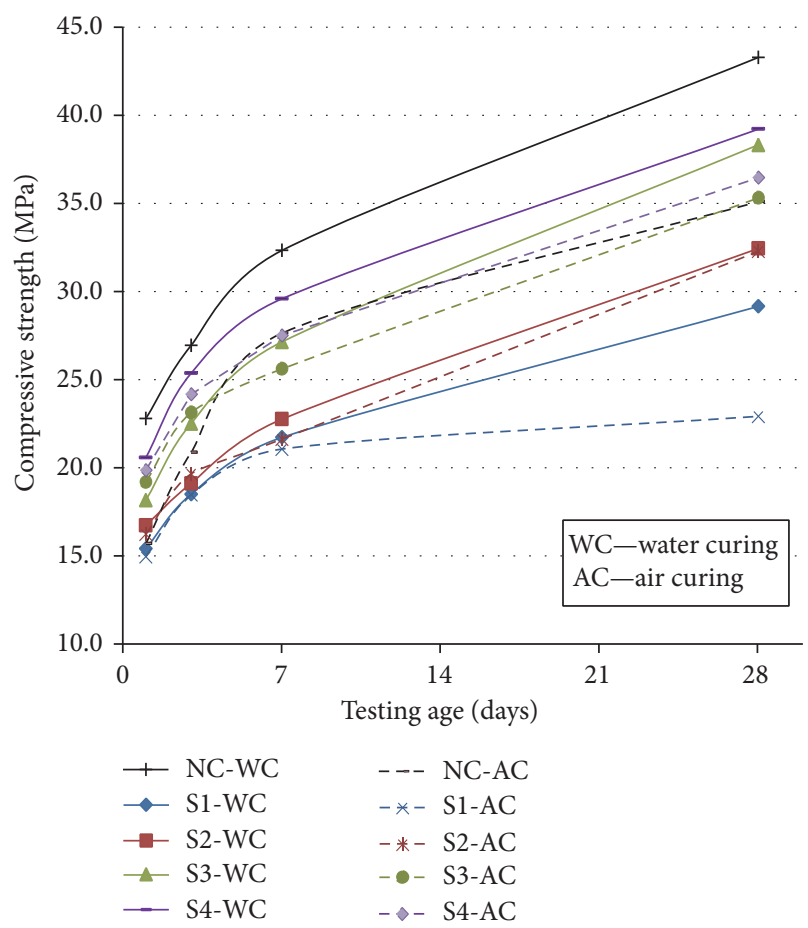

(b) Compressive strength of LWA40

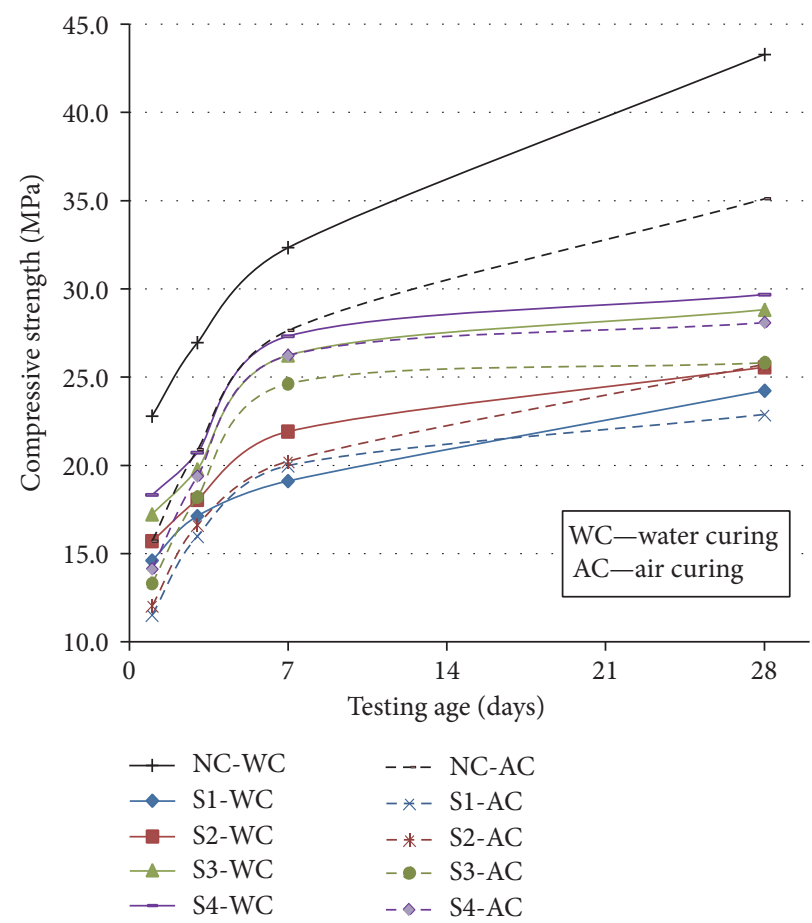

(c) Compressive strength of LWA60

FIGURE 11: Standard compressive strength test of NC and AAC-LWA concrete in different size classes (S1 to S4) at the age of 1, 3, 7, and 28 days. 


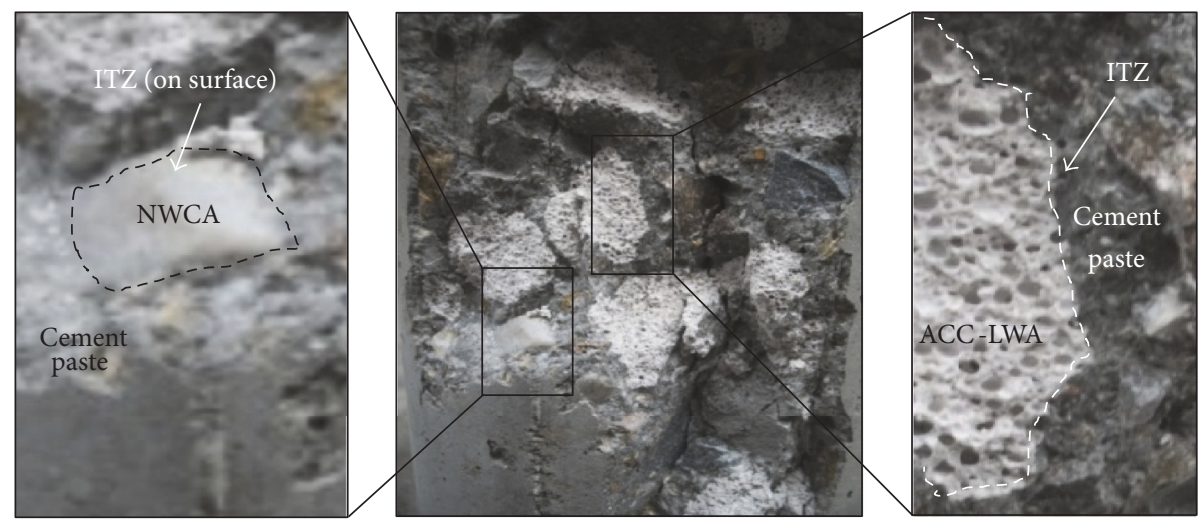

FIGURE 12: Normal-bonded NWCA (left) and well-bonded AAC-LWA (right) with cement paste on interfacial transition zone (ITZ).

TABLE 5: Differential percentage of minute compressive strength in layer 1 (L1) between exterior and interior zone.

\begin{tabular}{lcccccccccccc}
\hline \multirow{3}{*}{ Mixtures } & \multicolumn{3}{c}{ L1 7 d (MPa) } & \multicolumn{3}{c}{ L1 28 d (MPa) } & \multicolumn{3}{c}{ L1 7 d (MPa) } & \multicolumn{3}{c}{ Water curing (WC) } \\
& Ext. & Int. & $\% \Delta$ & Ext. & Int. & $\% \Delta$ & Ext. & Int. & $\% \Delta$ & Ext. & Int. & $\% \Delta$ \\
\hline NC & 0.64 & 0.95 & $\mathbf{4 8 . 4 7}$ & 0.84 & 1.30 & $\mathbf{5 4 . 1 3}$ & 0.77 & 1.03 & $\mathbf{3 4 . 4 8}$ & 1.21 & 1.54 & $\mathbf{2 7 . 8 6}$ \\
LWA20 & 0.83 & 1.12 & $\mathbf{3 4 . 0 0}$ & 1.12 & 1.69 & $\mathbf{5 1 . 1 0}$ & 1.11 & 1.41 & $\mathbf{2 6 . 9 8}$ & 1.48 & 2.01 & $\mathbf{3 5 . 3 2}$ \\
LWA40 & 0.93 & 1.30 & $\mathbf{3 9 . 0 3}$ & 1.00 & 1.55 & $\mathbf{5 4 . 9 9}$ & 1.26 & 1.57 & $\mathbf{2 3 . 8 2}$ & 1.32 & 1.73 & $\mathbf{3 0 . 7 4}$ \\
LWA60 & 0.93 & 1.23 & $\mathbf{3 2 . 0 0}$ & 1.13 & 1.62 & $\mathbf{4 2 . 9 3}$ & 1.15 & 1.39 & $\mathbf{2 1 . 6 4}$ & 1.43 & 1.80 & $\mathbf{2 5 . 5 1}$ \\
\hline
\end{tabular}

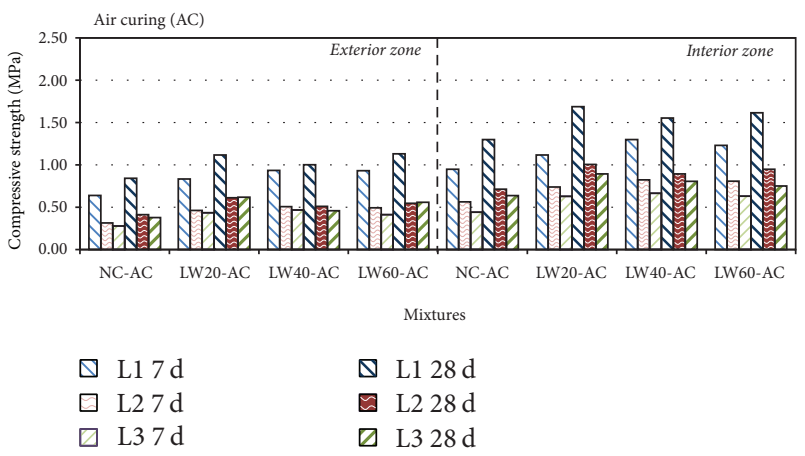

FIGURE 13: Minute compressive strength of NC and LWA mixtures at L1, L2, and L3 cured in the air (7 and 28 days of age).

a slight difference in compressive strength between water curing and air curing which water reserve of recycled AAC aggregate seems not necessary to provide moisture for further cement hydration process, the effectiveness of external curing may be limited due to an unsatisfied penetration of curing water into the samples, and the internal curing will then enlarge the positive curing regime from inside the concrete structure in the real use applications (e.g., huge structure or concrete component).

\section{Conclusions}

From the study, conclusion can be summarised as follows.

(1) The slump values were affected by the amount of water content. The slump value tended to rise with an increase

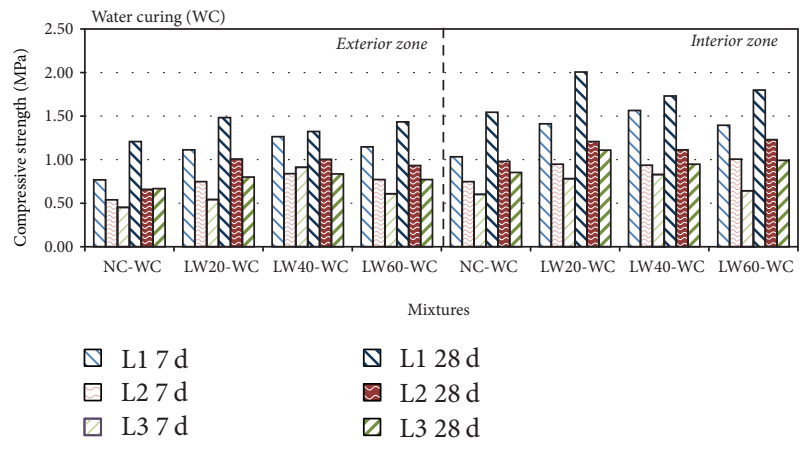

FIGURE 14: Minute compressive strength of NC and LWA mixtures at L1, L2, and L3 cured in the water (7 and 28 days of age).

of AAC-LWA replacement as extra water on aggregate's surface was obtained. However, flow values of all mixtures were similar to normal weight aggregate concrete (NC) and classified as medium consistency category with the flow of 50 to $60 \%$.

(2) The apparent density was decreased when the amount of AAC-LWA replacement increased from $2,380 \mathrm{~kg} / \mathrm{m}^{3}$ (NC) to around $2,050 \mathrm{~kg} / \mathrm{m}^{3}$ (LWA60). Although the minimum density in this test $\left(2,030 \mathrm{~kg} / \mathrm{m}^{3}\right.$ in LWA60 mixture) did not meet the criteria of lightweight concrete advised by ACI 213R87 at $1,850 \mathrm{~kg} / \mathrm{m}^{3}$, the lower value in density can alternatively be achieved by increasing AAC-LWA proportion or even using lightweight fine aggregates (e.g., lightweight sand or bottom ash). 


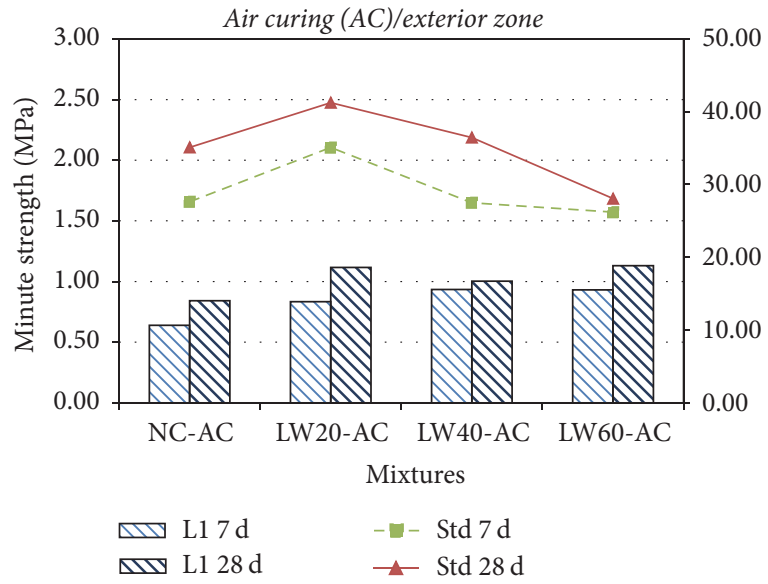

(a)

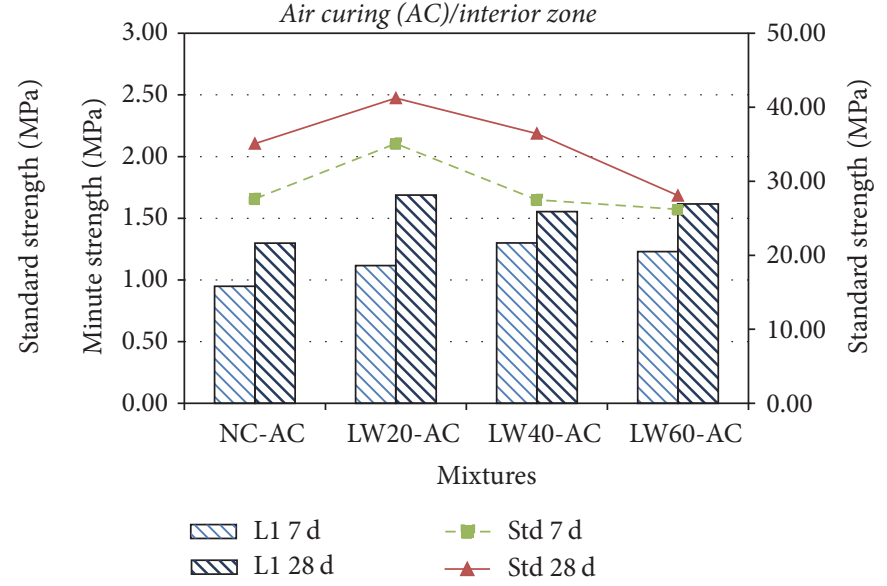

(b)

FIGURE 15: Relationship between standard and minute compressive strength of dry-air curing regime at (a) exterior zone and (b) interior zone.

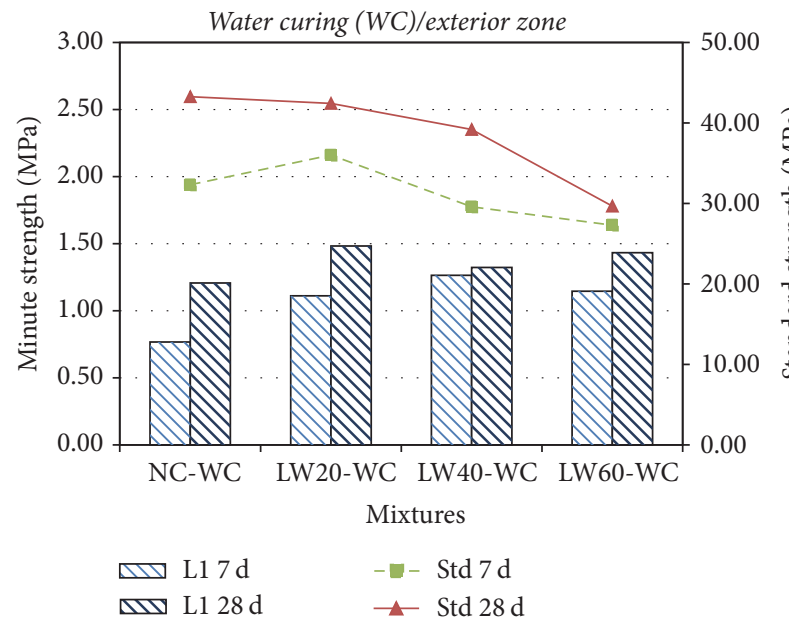

(a)

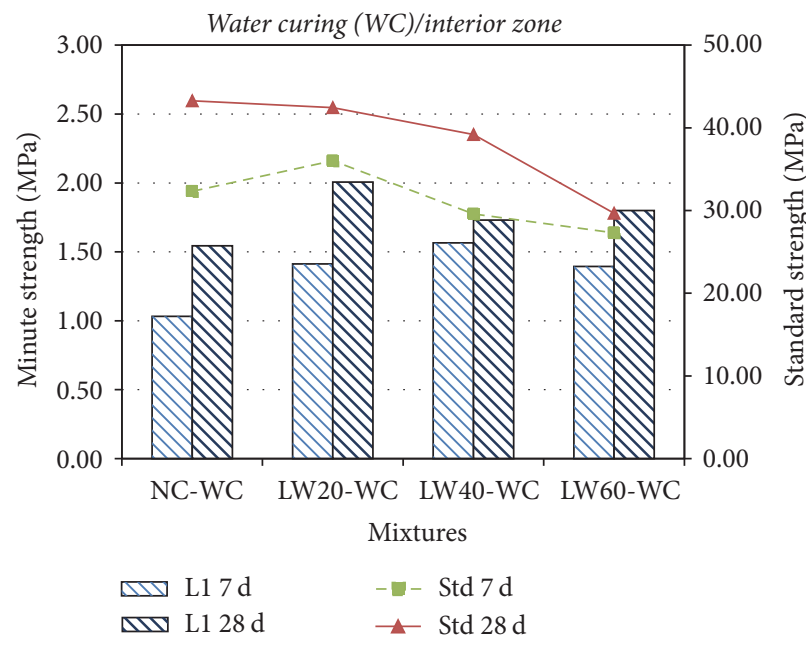

(b)

FIGURE 16: Relationship between standard and minute compressive strength of water curing regime at (a) exterior zone and (b) interior zone.

(3) The standard compressive strength by cylindrical specimens was decreased with higher AAC-LWA proportion in both dry-air and water curing, even though the water curing achieved slightly higher compressive strength. The mixed size of AAC-LWA (S4 class size) provided satisfactory gradation and superior strength than the single gradedaggregates (S1, S2, and S3).

(4) The highest strength of minute compressive test was achieved by $3 \times 3 \times 3 \mathrm{~mm}$. cube located in layer 1 (L1), followed by layer 2 (L2) and layer 3 (L3), respectively. It can be concluded that internal curing by AAC-LWA obviously improves the strength of concrete by providing extra internal water resource for more possible C-S-H formation. In conjunction with minute and standard compressive strength, the optimum proportions of AAC-LWA replacement were in the range of LWA20 to LWA40. Those mixture proportions mainly achieved the superior strength from normal weight aggregate while the suitable amount AAC aggregate replacement provided extra amount of water for internal curing to the cement paste.

(5) The development of AAC as a coarse aggregate replacement in concrete is not only utilising unwanted wastes from industry (recycling of waste materials) but also building up a new knowledge of using LWA as an internal curing agent as well as the production of value-added lightweight concrete products.

\section{Conflicts of Interest}

The authors declare that they have no conflicts of interest. 


\section{References}

[1] I.-J. Chiou, K.-S. Wang, C.-H. Chen, and Y.-T. Lin, "Lightweight aggregate made from sewage sludge and incinerated ash," Waste Management, vol. 26, no. 12, pp. 1453-1461, 2006.

[2] S. Zhao, C. Li, M. Zhao, and X. Zhang, "Experimental study on autogenous and drying shrinkage of steel fiber reinforced lightweight-aggregate concrete," Advances in Materials Science and Engineering, vol. 2016, Article ID 2589383, 9 pages, 2016.

[3] P. Lura, M. Wyrzykowski, C. Tang, and E. Lehmann, "Internal curing with lightweight aggregate produced from biomassderived waste," Cement and Concrete Research, vol. 59, pp. 2433, 2014.

[4] B. Akcay and M. A. Tasdemir, "Optimisation of using lightweight aggregates in mitigating autogenous deformation of concrete," Construction and Building Materials, vol. 23, no. 1, pp. 353-363, 2009.

[5] ACI Committee 213, Guild for Structural Lightweight Aggregate Concrete, American Concrete Institute, Detroit, Michigan, Mich, USA, 1999.

[6] K. M. A. Hossain, S. Ahmed, and M. Lachemi, "Lightweight concrete incorporating pumice based blended cement and aggregate: Mechanical and durability characteristics," Construction and Building Materials, vol. 25, no. 3, pp. 1186-1195, 2011.

[7] D. Sari and A. G. Pasamehmetoglu, "The effects of gradation and admixture on the pumice lightweight aggregate concrete," Cement and Concrete Research, vol. 35, no. 5, pp. 936-942, 2005.

[8] S. Weber and H. W. Reinhardt, "New generation of high performance concrete: concrete with autogeneous curing," Advanced Cement Based Materials, vol. 6, no. 2, pp. 59-68, 1997.

[9] T. Y. Lo, H. Z. Cui, and Z. G. Li, "Influence of aggregate prewetting and fly ash on mechanical properties of lightweight concrete," Waste Management, vol. 24, no. 4, pp. 333-338, 2004.

[10] W. Yodsudjai, Evaluation of strengths and choride ion diffusivity of minute regions in concrete using newly developed methods [Ph.D. thesis], Tokyo Institute of Technology, Japan, 2003.

[11] W. C. Tang, P. C. Ryan, H. Z. Cui, and W. Liao, "Properties of self-compacting concrete with recycled coarse aggregate," Advances in Materials Science and Engineering, vol. 2016, Article ID 2761294, 2016.

[12] M. Singh and R. Siddique, "Effect of coal bottom ash as partial replacement of sand on workability and strength properties of concrete," Journal of Cleaner Production, vol. 112, pp. 620-630, 2016.

[13] I. B. Topçu and B. Işikdağ, "Effect of expanded perlite aggregate on the properties of lightweight concrete," Journal of Materials Processing Technology, vol. 204, no. 1-3, pp. 34-38, 2008.

[14] P. Wattanachai, N. Otsuki, T. Saito, and R. Wongjeeraphat, "Influence of curing condition on the properties of mae moh fly ash mortar at surface and interior," in Proceedings of the Proceeding of the 6th Regional Symposium on Infrastructure Development, Bangkok, Thailand, January 2009.

[15] M. Suzuki, M. Seddik Meddah, and R. Sato, "Use of porous ceramic waste aggregates for internal curing of high-performance concrete," Cement and Concrete Research, vol. 39, no. 5, pp. 373-381, 2009.

[16] R. Kasemchaisiri and S. Tangtermsirikul, "A method to determine water retainability of porous fine aggregate for design and quality control of fresh concrete," Construction and Building Materials, vol. 21, no. 6, pp. 1322-1334, 2007. 

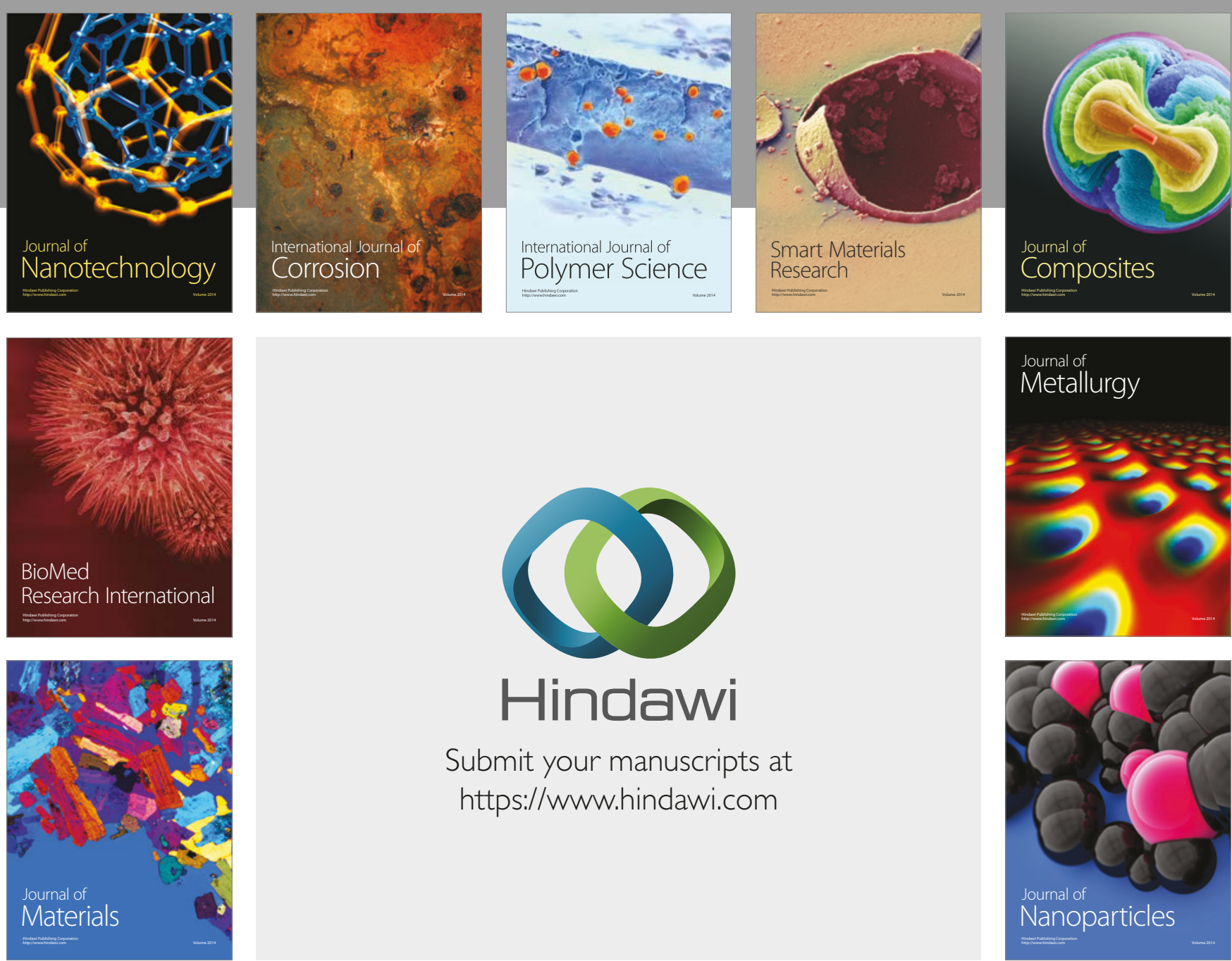

\section{Hindawi}

Submit your manuscripts at

https://www.hindawi.com
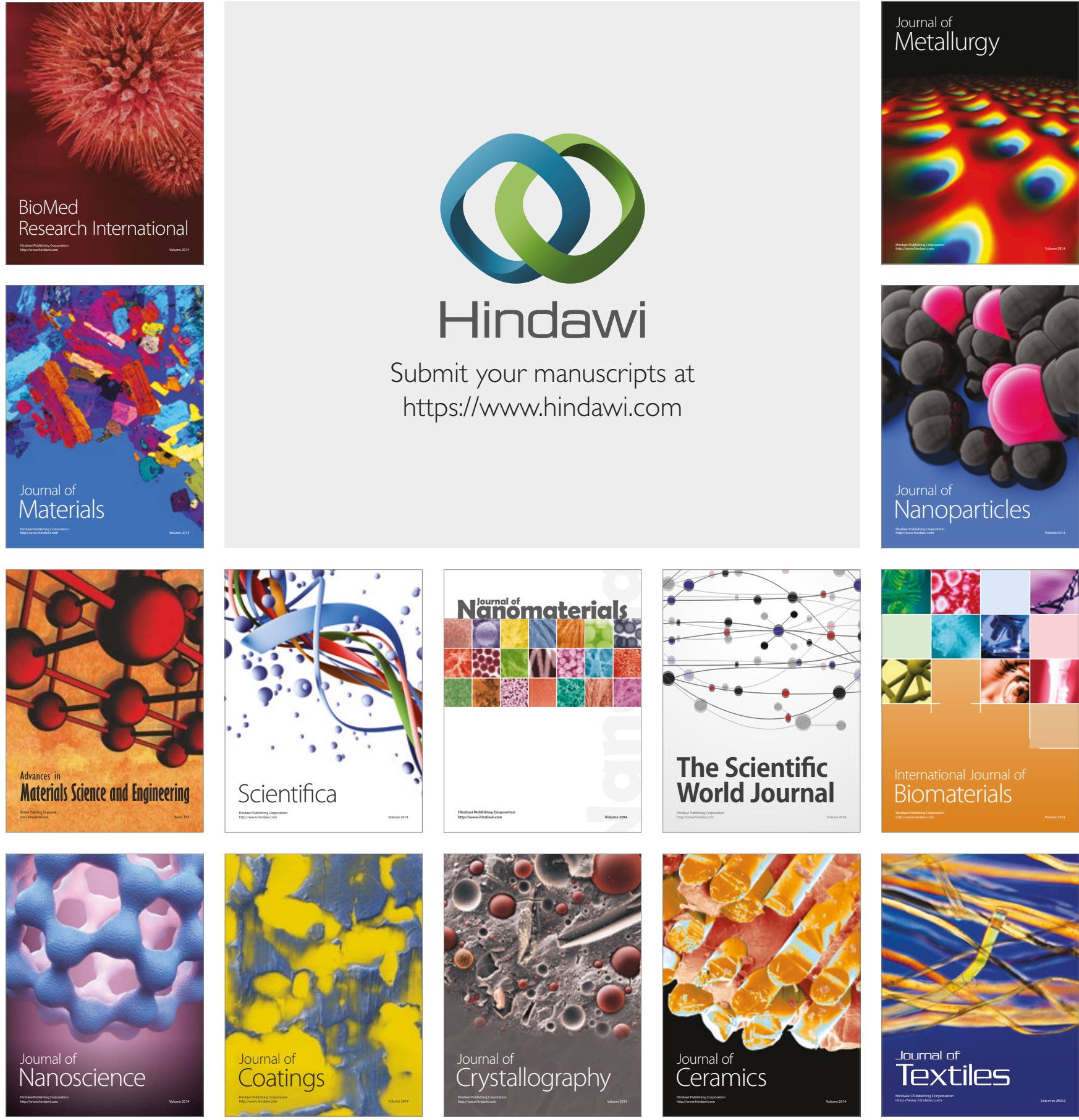

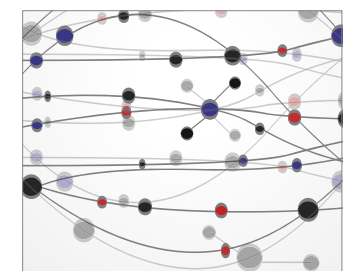

The Scientific World Journal
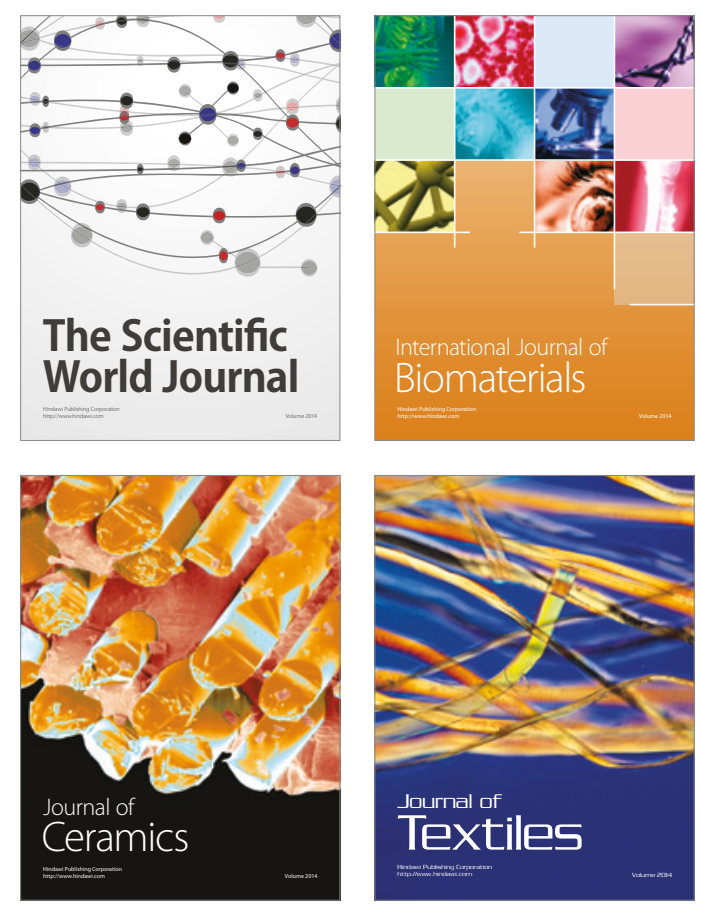